\title{
Characteristics of tropopause parameters as observed with GPS radio occultation
}

\author{
T. Rieckh ${ }^{1,2}$, B. Scherllin-Pirscher ${ }^{1,2}$, F. Ladstädter ${ }^{1,2}$, and U. Foelsche ${ }^{2,1}$ \\ ${ }^{1}$ Wegener Center for Climate and Global Change, University of Graz, Graz, Austria \\ ${ }^{2}$ Institute for Geophysics, Astrophysics, and Meteorology/Institute of Physics (IGAM/IP), University of Graz, Graz, Austria \\ Correspondence to: T. Rieckh (therese.rieckh@uni-graz.at)
}

Received: 15 April 2014 - Published in Atmos. Meas. Tech. Discuss.: 8 May 2014

Revised: 15 October 2014 - Accepted: 18 October 2014 - Published: 26 November 2014

\begin{abstract}
Characteristics of the lapse rate tropopause are analyzed globally for tropopause altitude and temperature using global positioning system (GPS) radio occultation (RO) data from late 2001 to the end of 2013. RO profiles feature high vertical resolution and excellent quality in the upper troposphere and lower stratosphere, which are key factors for tropopause determination, including multiple ones. RO data provide measurements globally and allow examination of both temporal and spatial tropopause characteristics based entirely on observational measurements. To investigate latitudinal and longitudinal tropopause characteristics, the mean annual cycle, and inter-annual variability, we use tropopauses from individual profiles as well as their statistical measures for zonal bands and $5^{\circ} \times 10^{\circ}$ bins. The latitudinal structure of first tropopauses shows the well-known distribution with high (cold) tropical tropopauses and low (warm) extra-tropical tropopauses. In the transition zones (20 to $40^{\circ} \mathrm{N} / \mathrm{S}$ ), individual profiles reveal varying tropopause altitudes from less than $7 \mathrm{~km}$ to more than $17 \mathrm{~km}$ due to variability in the subtropical tropopause break. In this region, we also find multiple tropopauses throughout the year. Longitudinal variability is strongest at northern hemispheric mid latitudes and in the Asian monsoon region. The mean annual cycle features changes in amplitude and phase, depending on latitude. This is caused by different underlying physical processes (such as the Brewer-Dobson circulation - BDC) and atmospheric dynamics (such as the strong polar vortex in the southern hemispheric winter). Inter-annual anomalies of tropopause parameters show signatures of El Niño-Southern Oscillation (ENSO), the quasi-biennial oscillation (QBO), and the varying strength of the polar vortex, including sudden stratospheric warming (SSW) events. These results are
\end{abstract}

in good agreement with previous studies and underpin the high utility of the entire RO record for investigating latitudinal, longitudinal, and temporal tropopause characteristics globally.

\section{Introduction}

The tropopause marks the transition between the well-mixed troposphere and the stably stratified stratosphere. Besides the change in stratification, fundamental changes in the composition of chemical constituents, such as water vapor or ozone, take place in this region (Holton et al., 1995). The tropopause generally acts as a dynamic barrier for cross-tropopause transport. In the tropics, exchange between the troposphere and the stratosphere is mainly determined by the upwelling branch of the Brewer-Dobson circulation (BDC) and by deep convection. Tropical cross-tropopause transport is the main source of water vapor in the stratosphere and plays an important role in stratospheric chemistry and its radiative budget (Fueglistaler et al., 2009). In the extra-tropics, stratospheretroposphere exchange takes place via quasi-horizontal transport at the edge of subtropical and polar jets, affecting tropospheric ozone concentrations and, hence, tropospheric and surface climate (Gettelman et al., 2011).

Tropopause properties not only contain information about possible troposphere-stratosphere exchange, but they can also be associated with the state of certain atmospheric characteristics. For example, due to their simple latitudinal structure, tropopause pressure or tropopause altitude characteristics can serve as a measure for the width of the tropical belt (Seidel and Randel, 2007; Birner, 2010b). 
Tropopause characteristics react to both tropospheric and stratospheric temperature changes. Studies about tropopause altitude changes as an indicator of climate change have been conducted by Santer et al. (2003), Sausen and Santer (2003), and Seidel and Randel (2006), to name a few. All these studies have consistently found evidence of a decrease in global tropopause temperature and pressure (increase in tropopause altitude) due to anthropogenic tropospheric warming and lower stratospheric cooling (e.g., Santer et al., 2004).

Over the last decades, radiosonde data have been the most important observational data source to study tropopause parameters and their characteristics (Randel et al., 2000; Seidel et al., 2001). With their multiple-decade data record and high vertical resolution, these measurements are very valuable for monitoring inter-annual and intra-annual variations of tropopause parameters. On the other hand, coverage in the Southern Hemisphere ( $\mathrm{SH}$ ) and above oceans is very poor, which makes it hard to catch spatial characteristics and changes. Thus, analysis and reanalysis products have been additionally used to investigate tropopause characteristics globally (see, e.g., Hoinka, 1998; Highwood and Hoskins, 1998).

However, to investigate tropopause properties based only on observational data, the relatively new global positioning system (GPS) radio occultation (RO) technique delivers well-suited data. The RO method (Melbourne et al., 1994; Kursinski et al., 1997; Hajj et al., 2002; Kuo et al., 2004) provides near-vertical profiles of atmospheric thermodynamic variables with high vertical resolution (better than $1 \mathrm{~km}$ ) and global coverage. Other features of RO measurements include all-weather capability, high accuracy, high precision, and long-term stability (Anthes, 2011). A number of studies confirmed the feasibility and excellent eligibility of RO measurements for monitoring the atmosphere (Foelsche et al., 2008, 2009) and for climate change detection (Leroy et al., 2006; Schmidt et al., 2008; Steiner et al., 2011).

The combination of the excellent RO profile quality in the upper troposphere and lower stratosphere (Kursinski et al., 1997) and data availability above ocean and land (including polar regions) make these data highly suited for tropopause parameter evaluation. The first studies using GPS RO data for tropopause determination were conducted by Nishida et al. (2000), Randel et al. (2003), and Schmidt et al. (2004) for the tropical region. As RO data proved to provide accurate information on tropopause characteristics, these data have been increasingly used in recent years (Kishore et al., 2006; Borsche et al., 2007; Foelsche et al., 2009; Son et al., 2011). Recently, a new method for tropopause determination from RO profiles based on bending angle information has been introduced by Lewis (2009). This technique can be applied earlier in the RO data retrieval, avoiding additional processing. Schmidt et al. (2010) compared tropopause data resulting from this algorithm to conventional lapse rate tropopause data and found generally good agreement.
In this work, we take advantage of having more than 12 years of RO observational data available. We use the dense field of RO profiles to compute multi-year statistics of tropopause altitude and temperature and to analyze El Niño-Southern Oscillation (ENSO)- and quasi-biennial oscillation (QBO)-related variability on a small scale. Interannual anomalies of tropopause altitude and temperature depict the strong stratospheric influence at high latitudes. Our results confirm those of previous studies, but show climatological tropopause characteristics for the longer RO record available now.

The structure of this paper is as follows: in Sect. 2, a description of the RO measurement principle, the tropopause algorithm, and the binning and statistical methods is given. In Sect. 3, latitudinal and longitudinal characteristics are discussed. Section 4 describes the annual cycle of averaged tropopause data for different latitudinal bands, and, in Sect. 5, inter-annual variability is discussed. Section 6 provides a summary.

\section{Data and methods}

\subsection{RO measurement principle}

The GPS RO method is a limb sounding technique and uses electromagnetic signals transmitted by GPS satellites, which are received by a low Earth orbit (LEO) satellite. The GPS signals are delayed and refracted by the Earth's atmosphere. The measured quantity onboard the LEO satellite is the phase change as a function of time between the intrinsically transmitted signal and the received frequency-shifted signal. Due to the satellites' motion, the atmosphere is scanned, which yields a profile of phase changes. By including precise orbit information, it can be transformed into a bending angle profile. Using an Abel transform, bending angle profiles are processed to refractivity profiles.

To first order, refractivity depends on dry air density and humidity, as described by the Smith-Weintraub formula (Smith and Weintraub, 1953). In the so-called dry air retrieval, presence of water vapor is attributed to the dry atmospheric parameters. Applying the Smith-Weintraub formula, hydrostatic equation, and the equation of state yields dry density, dry temperature, and dry pressure. For a detailed retrieval description, see Kursinski et al. (1997). Physical atmospheric parameters can be derived by including background information and applying a 1D-Var retrieval (Healy and Eyre, 2000).

For tropopause computation, we use quality-controlled atmospheric profiles retrieved with the Wegener Center for Climate and Global Change (WEGC) Occultation Processing System (OPS), version 5.6 (Schwärz et al., 2013) from the following satellite missions: CHAMP (CHAllenging MiniSatellite Payload) - September 2001 to September 2008; SAC-C (Satélite de Aplicaciones Científicas/Scientific Ap- 


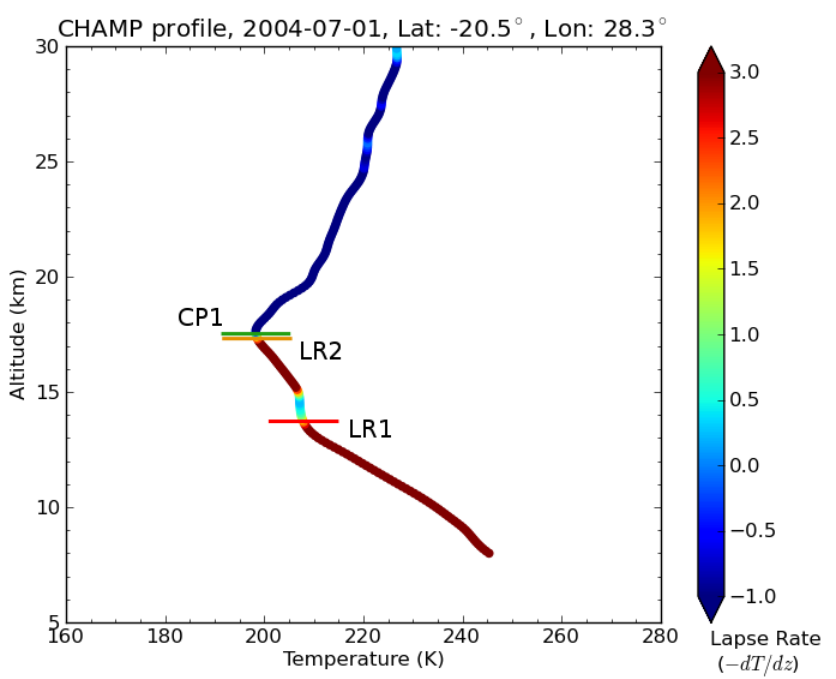

Figure 1. CHAMP temperature profile colored according to its lapse rate. Horizontal bars indicate the lowest (first) lapse rate tropopause (LR1), second lapse rate tropopause (LR2), and the local minimum of the profile, the cold point tropopause (CP1). Note the decrease in temperature above LR1, fulfilling the requirement for a second tropopause (lapse rate greater than $3^{\circ} \mathrm{C} \mathrm{km}^{-1}$ ).

plications Satellite C) - March 2006 to August 2011; F3C (Formosa Satellite Mission 3/Constellation Observing System for Meteorology, Ionosphere, and Climate) - April 2006 to December 2013; GRACE-A (Gravity Recovery And Climate Experiment) - March 2007 to December 2013. During the CHAMP period, approximately 5000 profiles per month were available globally. The number of measurements strongly increased to approximately 60000 profiles per month with the launch of the six F3C satellites. The investigated time range covers September 2001 through December 2013.

\subsection{Tropopause algorithm}

There exist several tropopause definitions, such as the chemical, dynamical, or thermal definition. The lapse rate definition has the advantage that it is easy to apply and commonly used, which allows comparison to other studies. We therefore apply the lapse rate tropopause definition of the World Meteorological Organization (WMO) to individual RO temperature profiles and compute tropopause altitude $H_{\mathrm{T}}$ and temperature $T_{\mathrm{T}}$. According to the WMO (1957), the tropopause is defined as the lowest level at which the lapse rate decreases to $2{ }^{\circ} \mathrm{C} \mathrm{km}^{-1}$ or less, provided that the average lapse rate from this point to any other point within the next $2 \mathrm{~km}$ does not exceed $2{ }^{\circ} \mathrm{C} \mathrm{km}^{-1}$ either. This ensures that one does not accidentally mistake a shallow stable layer in the troposphere for the tropopause (Homeyer et al., 2010). For the profile shown in Fig. 1, this criterion is fulfilled at $13.5 \mathrm{~km}$.

For multiple tropopauses, the WMO (1957) states that, if, at any point above the first tropopause, the average lapse rate between this point and any point within the next higher kilometer exceeds $3^{\circ} \mathrm{C} \mathrm{km}^{-1}$, an additional tropopause may be found using the same criterion as before. In Fig. 1, the lapse rate exceeds $3^{\circ} \mathrm{C} \mathrm{km}^{-1}$ between 15 and $17 \mathrm{~km}$. At $17.3 \mathrm{~km}$, a second lapse rate tropopause is found. The local minimum of the temperature profile - i.e., the cold point tropopause is located slightly higher at $17.5 \mathrm{~km} . T_{\mathrm{T}}$ is computed directly from the temperature profile by choosing the value according to $H_{\mathrm{T}}$.

To obtain tropopause altitudes, it is necessary to consider the vertical resolution of the atmospheric profiles (Reichler et al., 2003; Birner, 2006). For the high-resolution RO profiles, we use cubic spline interpolation that passes through all initially given data points and apply the tropopause algorithm on a $20 \mathrm{~m}$ grid. This method fits well to the physical structure of temperature profiles close to the tropopause. We apply the tropopause algorithm to dry temperature profiles as differences between dry and physical temperatures become negligible at tropopause altitudes for most latitudes (ScherllinPirscher et al., 2011; Danzer et al., 2014). However, high concentrations of water vapor in the lower troposphere can lead to temperature gradients, which may be interpreted as tropopauses by the tropopause algorithm. In order to exclude these "tropopauses", we compared tropopause altitudes from dry RO temperature profiles (which include water vapor variations) and from physical RO temperature profiles (which do not include water vapor variations) and analyzed water vapor influence. Based on this empirical analysis, we identified lower bounds for each $10^{\circ}$ latitude band and each month. We specified these lower limits to be approximately $5 \mathrm{~km}$ at winter high latitudes, $6 \mathrm{~km}$ at summer high latitudes and winter mid latitudes, $8 \mathrm{~km}$ at summer mid latitudes, and $12 \mathrm{~km}$ in the tropics. For details, see Rieckh (2013).

Furthermore, we restrict the algorithm to a top altitude of $22 \mathrm{~km}$. Figure 2 exemplarily shows dry temperature profiles and their tropopauses for January 2004 with all constraints described above.

\subsection{Binning and statistical methods}

We investigate tropopause characteristics for 5 and $10^{\circ}$ zonal bands (from 2001 to 2013) and for fine-resolved $5^{\circ} \times 10^{\circ}$ latitude-longitude bins (from 2007 to 2013 only, when there are enough data available). Multi-year monthly statistical measures include the latitude-weighted mean and its standard deviation, as well as median, quartiles, and extreme values (summarized in box-and-whisker plots). Inter-annual anomalies are obtained by subtracting the mean annual cycle at each grid point.

To analyze ENSO- and QBO-related variability of tropopause parameters, we apply an ordinary least squares (OLS) regression model to inter-annual anomalies, using proxy data for ENSO (monthly means of sea surface tem- 


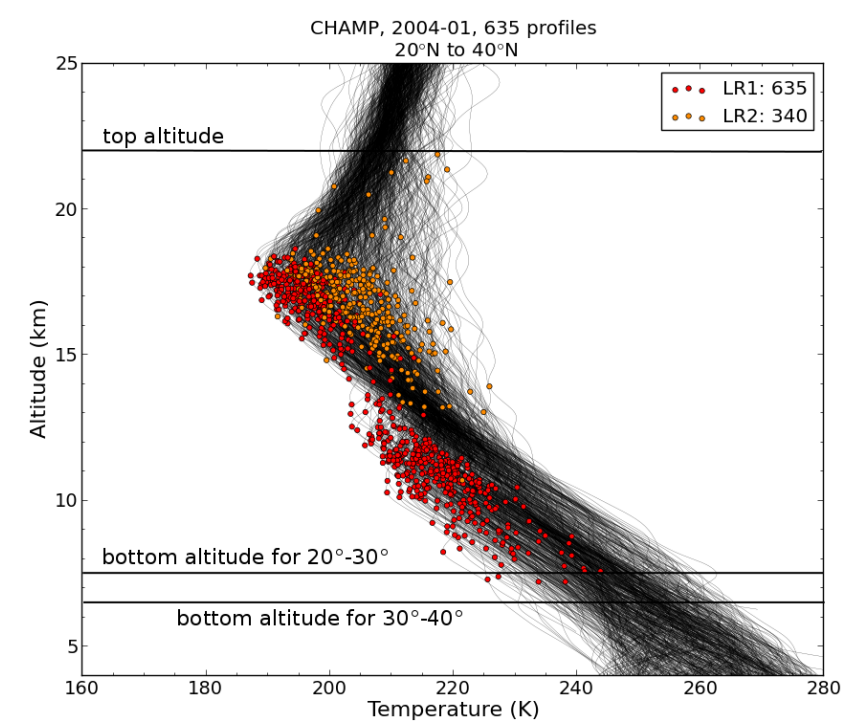

Figure 2. CHAMP temperature profiles and their tropopauses between 20 and $40^{\circ} \mathrm{N}$ in January 2004. First tropopause: red; second tropopause: orange. Top and bottom altitudes of the tropopause algorithm are indicated by horizontal lines.

perature (SST), Niño 3.4) ${ }^{1}$ and QBO (Singapore winds at $50 \mathrm{hPa})^{2}$. For the regression we assume that tropopause characteristics respond to the ENSO SST proxy with a lag of 3 months, and precede the QBO wind proxy by 3 months (Baldwin et al., 2001; Steiner et al., 2013). The statistical significance of the regression is assessed by applying a Student's $t$ test at the $95 \%$ confidence level.

\section{Spatial characteristics}

\subsection{Latitudinal characteristics}

Figure 3 shows the statistics of the first (lowest) tropopause altitude $\left(H_{\mathrm{T}}\right)$ for January and July. Two well-defined regions can be distinguished. While tropical tropopauses are mainly found at 16 to $17 \mathrm{~km}$, extra-tropical tropopauses occur at lower altitudes between 8 and $12 \mathrm{~km}$. This pattern results from combined effects of the troposphere and the stratosphere. While the surface pressure and tropospheric lapse rates determine these basic latitudinal characteristics (e.g., Held, 1982; Thuburn and Craig, 1997), stratospheric dynamics can also significantly raise or lower tropopause height (e.g., Son et al., 2007; Birner, 2010a).

For most latitudes and seasons, the distributions are symmetric: mean $\left(H_{\text {mean }}\right)$ and median $\left(H_{\text {med }}\right)$ show good agreement (differences smaller than $500 \mathrm{~m}$ ) and the median lies at the center of the box ( 25 to 75 quartile). The boxes cover

\footnotetext{
${ }^{1}$ http://www.cpc.ncep.noaa.gov/data/indices/ersst3b.nino.mth. 81-10.ascii

${ }^{2}$ http://www.cpc.ncep.noaa.gov/data/indices/qbo.u50.index
}
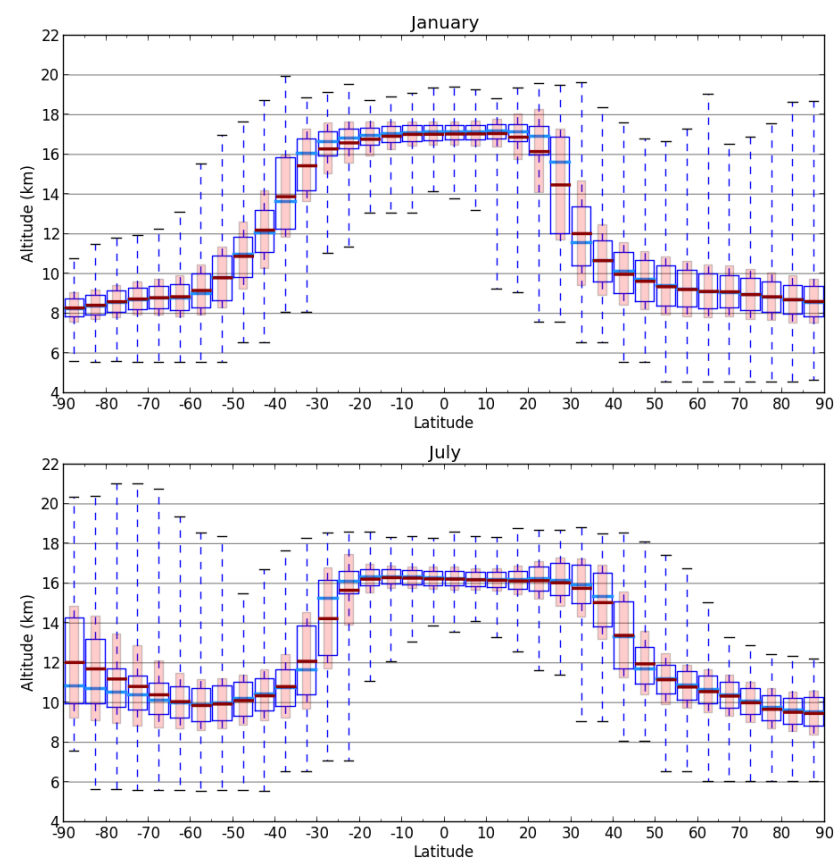

Figure 3. Altitudes of the first tropopause versus latitude for January (top) and July (bottom) from 2001 to 2013. Shown are the mean (dark red line), one standard deviation (bright red bars), median (blue bar), 25 to 75 quartile (box), and extreme values (whiskers) for $5^{\circ}$ latitudinal bands.

$1 \mathrm{~km}$ in the tropics and less than $2 \mathrm{~km}$ in the extra-tropics. The standard deviation covers $1.5 \mathrm{~km}$ in the tropics and 1.5 to $3 \mathrm{~km}$ in the extra-tropics. In the subtropics $\left(20\right.$ to $\left.30^{\circ}\right)$, the spread becomes much larger due to the transition from tropical to extra-tropical tropopause characteristics. Furthermore, large deviations between mean and median are found, and the distribution is skewed in the hemispheric winter. Variability in the subtropical tropopause break leads to large variations in the $H_{\mathrm{T}}$ distribution. The higher median compared to the mean and the position of the median relative to the quartiles indicates that the major part of tropopauses is located at high altitudes. The few tropopauses with extra-tropical characteristics lower the mean significantly.

Differences between $H_{\text {mean }}$ and $H_{\text {med }}$ can also be found at high latitudes in winter in the SH. Extremely high values of $H_{\mathrm{T}}$, as found between 12 and $18 \mathrm{~km}$, raise the mean, and differences between mean and median exceed $1 \mathrm{~km}$. These high $H_{\mathrm{T}}$ may result from a deficiency of the lapse rate tropopause definition, because it is not well suited for very cold stratospheric conditions, as found in the southern hemispheric polar winter (Zängl and Hoinka, 2001).

In Fig. 4, statistics of tropopause temperature $\left(T_{\mathrm{T}}\right)$ are shown for January and July as a function of latitude. Generally, tropopause temperature inversely correlates with tropopause altitude. High tropical tropopauses feature low temperatures with a mean $T_{\mathrm{T}}$ of $190 \mathrm{~K}$ in January and $195 \mathrm{~K}$ in July. Lower and therefore warmer extra-tropical 

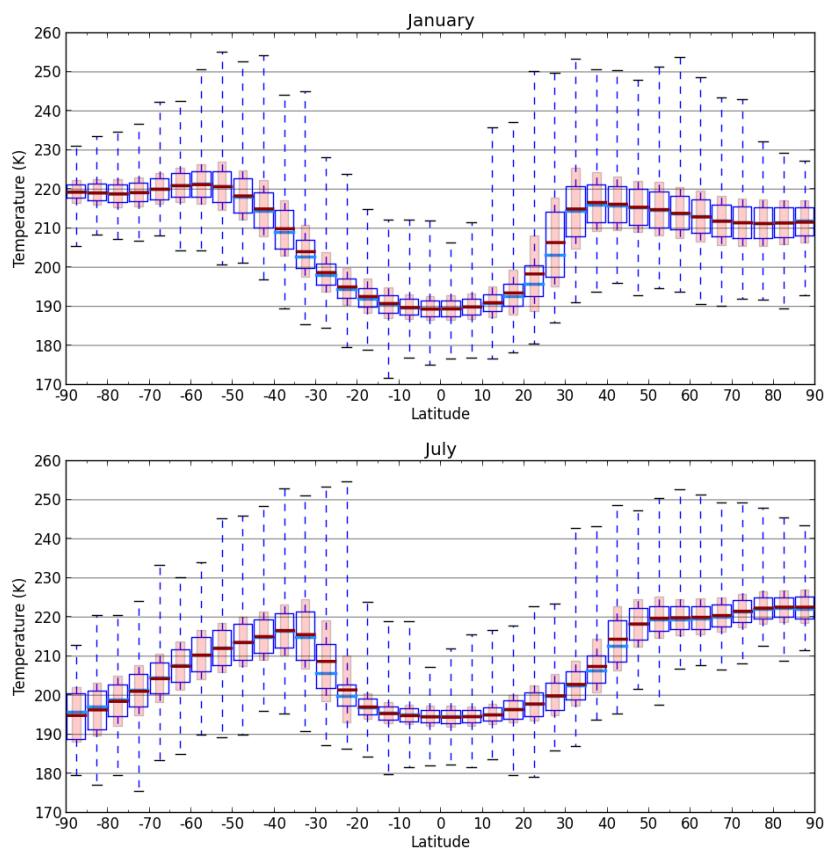

Figure 4. Temperatures of the first tropopause versus latitude for January (top) and July (bottom) from 2001 to 2013. Shown are the mean (dark red line), one standard deviation (bright red bars), median (blue bar), 25 to 75 quartile (box), and extreme values (whiskers) for $5^{\circ}$ latitudinal bands.

tropopauses reach mean temperatures of $220 \mathrm{~K}$ in the summer hemisphere and $215 \mathrm{~K}$ in the winter hemisphere. At southern hemispheric high latitudes, the mean drops to $195 \mathrm{~K}$ due to the extremely cold polar vortex in austral winter. $T_{\mathrm{T}}$ extremes range from less than $175 \mathrm{~K}$ in the tropics to more than $255 \mathrm{~K}$ in the extra-tropics.

As for $H_{\mathrm{T}}$, larger differences between mean $\left(T_{\text {mean }}\right)$ and median $\left(T_{\text {med }}\right)$ are found between 20 and $30^{\circ}$ in hemispheric winter. $T_{\text {mean }}$ is up to $4 \mathrm{~K}$ higher than $T_{\text {med }}$. However, the differences in $H_{\text {mean }}$ and $H_{\text {med }}$ in the southern hemispheric polar winter are not found in $T_{\text {mean }}$ and $T_{\text {med }}$ because of the cold and stably stratified, nearly isothermal, stratosphere.

Figure 5 shows the altitude distribution of individual tropopauses for January and July for the exemplary year 2008. Monthly mean and median are shown for $5^{\circ}$ latitudinal bands. The sharp, stepwise edges of lowermost occurring tropopauses in the subtropics and mid latitudes are due to a combination of the bottom search altitude, as defined in the tropopause algorithm (see Sect. 2.2) and dry temperature variations caused by changing water vapor concentrations. These variations may be occasionally identified as tropopauses by the algorithm.

In Fig. 5, the different tropopause characteristics in the winter and summer hemisphere can be seen in the subtropics for the individual tropopauses. In the summer hemisphere, the transition from tropical to extra-tropical $H_{\mathrm{T}}$ is rather smooth. In the winter hemisphere, there is a jump from trop-
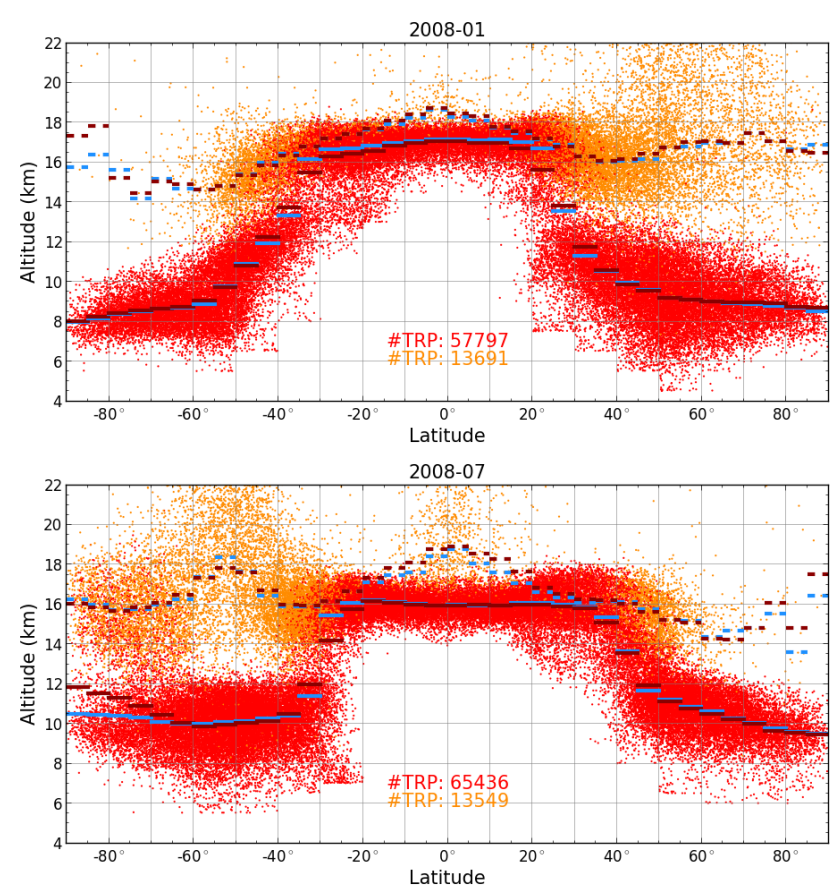

Figure 5. Altitudes of the first (lowest; red) and second (orange) tropopause versus latitude for January (top) and July (bottom) 2008. Mean (dark red) and median (blue) of first (solid) and second (dashed) tropopause of $5^{\circ}$ latitudinal bands are indicated by horizontal lines.

ical to extra-tropical characteristics between 20 and $30^{\circ} \mathrm{N} / \mathrm{S}$ rather than a steady decrease of $H_{\mathrm{T}}$ with latitude. This leads to a large spread of $H_{\mathrm{T}}$, covering more than $10 \mathrm{~km}$.

Figure 5 also shows the latitudinal distribution of second tropopauses. Double tropopauses mainly occur at subtropical latitudes throughout the year and at mid and high latitudes in winter, when the jet is stronger. Double tropopauses close to the subtropical jet are associated with latitudinal migration of the tropical over the subtropical tropopause (Randel et al., 2007). In the winter hemisphere, double tropopause occurrence expands further polewards, reflecting the unstable stratospheric conditions with low stratification. Double tropopauses mainly occur between 14 and $20 \mathrm{~km}$ (multiyear statistics; not shown). Fewer double tropopauses can be found in the tropics. They can be found throughout the year and are likely caused by planetary scale waves. Equatorial Kelvin waves with strong amplitudes can modify the temperature profile and thus its lapse rate, which can lead to double tropopauses (Randel et al., 2007). Second tropopauses in the tropics spread between 16 and $22 \mathrm{~km}$. Mean and median of second tropopauses are generally in good agreement as differences rarely exceed $200 \mathrm{~m}$ (multi-year statistics).

\subsection{Longitudinal characteristics}

Longitudinal variations in $H_{\mathrm{T}}$ and $T_{\mathrm{T}}$ occur due to land and sea coverage and orography. Figure 6 shows the multi-year 


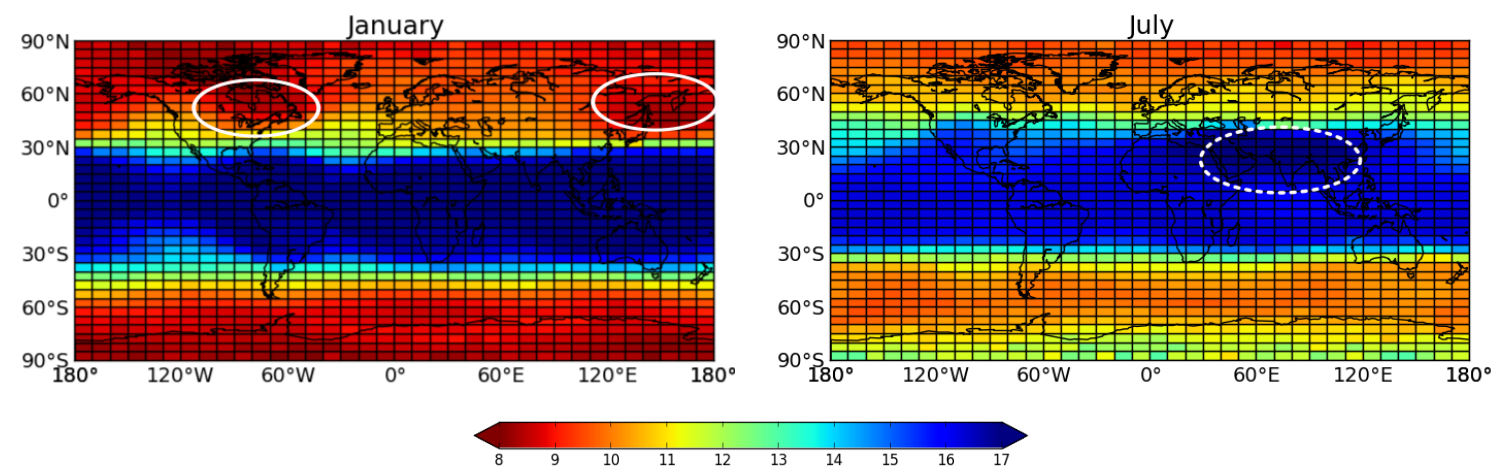

Figure 6. Mean altitude $(\mathrm{km})$ of first tropopauses for January and July from 2007 to 2013 . White circles denote areas of exceptionally low (solid) and high (dashed) tropopauses within the respective latitude band.

monthly mean $H_{\mathrm{T}}$ for January and July. It is obvious that longitudinal variations of tropopause parameters are much smaller than latitudinal variations.

Zonal asymmetries appear especially at mid latitudes (40 to $60^{\circ} \mathrm{N}$ ) in the Northern Hemisphere (NH). These asymmetries are strongest in winter, but can still be found in spring and fall (not shown). For January, Fig. 6 shows exceptionally low $H_{\mathrm{T}}$ above eastern Canada, as well as above eastern Russia and the western part of the North Pacific (white solid circles). This pattern occurs due to large-scale Rossby wave troughs at the eastern side of continents (Zängl and Hoinka, 2001). $H_{\mathrm{T}}$ varies between less than 8 and $9 \mathrm{~km}$ in these areas, while $H_{\mathrm{T}}$ is at 9 to $12 \mathrm{~km}$ above the eastern North Pacific and North Atlantic. The pattern becomes weaker in spring. During summer, these zonal asymmetries vanish as Rossby wave activity is weakest during that time of the year.

Figure 6 also shows zonal asymmetries in the tropics/subtropics in summer (July) in the NH. $H_{\mathrm{T}}$ reaches more than $17 \mathrm{~km}$ above South Asia (white dashed circle), which is approximately $1 \mathrm{~km}$ higher than the zonal mean. This pattern is caused by deep convective activity in the Asian monsoon region (Highwood and Hoskins, 1998).

Zonal asymmetries are less pronounced in the $\mathrm{SH}$ for the multi-year average.

$T_{\mathrm{T}}$ generally shows zonal patterns similar to $H_{\mathrm{T}}$, such as a strong zonal asymmetry in boreal winter at northern hemispheric mid latitudes.

\section{The annual cycle}

Figure 7 shows the mean annual cycle for the mean and median of $H_{\mathrm{T}}$ and $T_{\mathrm{T}}$ for $10^{\circ}$ latitudinal bands. Generally, $H_{\mathrm{T}}$ follows the cycle of incoming radiation, with maximum altitudes in summer, a decrease in fall, minimum altitudes in winter, and an increase in spring. The mean annual cycle is very pronounced in the subtropics and at mid latitudes, with amplitudes of more than $2 \mathrm{~km}$. The amplitude decreases towards the tropics and high latitudes. In the tropics, the an- nual cycle is weak as $H_{\mathrm{T}}$ changes are only about $1 \mathrm{~km}$. In the northern hemispheric tropics, between the Equator and $20^{\circ} \mathrm{N}, H_{\mathrm{T}}$ shows an annual cycle with maximum altitudes in winter and minimum altitudes in summer due to the strong influence of the BDC on $H_{\mathrm{T}}$. The BDC northern hemispheric branch has a strong annual cycle, with maximum tropical upwelling in winter. As a result, tropical tropopause altitudes increase in winter, following the strong increase of equatorial upwelling (Yulaeva et al., 1994).

At high latitudes, the mean annual cycle of $H_{\mathrm{T}}$ fundamentally behaves differently for the $\mathrm{NH}$ and the $\mathrm{SH}$. In the $\mathrm{NH}$, the annual cycle is a combination of two waves. It consists of a single wave pattern over subpolar eastern Siberia and North America with maximum $H_{\mathrm{T}}$ in boreal summer (minimum $H_{\mathrm{T}}$ in boreal winter), and a double wave pattern over northern Europe, western Siberia, and high Arctic latitudes with maximum $H_{\mathrm{T}}$ in summer and winter in the $\mathrm{NH}$ (minimum $H_{\mathrm{T}}$ in spring and fall in the $\mathrm{NH}$ ) (Zängl and Hoinka, 2001). In the SH, a reversed mean annual cycle occurs over Antarctica. It can be explained by the gradual decrease of stratospheric temperatures during austral winter due to the lack of incoming radiation. Minimum stratospheric temperatures and thus highest $H_{\mathrm{T}}$ are observed in August. Due to the shift in phase from mid latitudes to high latitudes, there is no pronounced cycle at all for the latitudinal band 50 to $60^{\circ} \mathrm{S}$.

The comparison of mean and median shows good agreement, except for the latitudinal bands 20 to $30^{\circ} \mathrm{N} / \mathrm{S}$. Differences between mean and median in these regions have already been found for January and July, as shown in Fig. 5. However, the complete annual cycle gives further insight in the development of tropopause distribution. In the $\mathrm{NH}$, the median has a very weak annual cycle that follows that of the tropical tropopauses. Due to strong equatorial upwelling in winter in the $\mathrm{NH}$, most tropopauses are pushed to high altitudes even within the 20 to $30^{\circ} \mathrm{N}$ latitudinal band. The mean, on the other hand, is strongly affected by the very low tropopauses occurring in this region (see Fig. 5). In boreal summer, such low tropopauses do not occur due to the smooth decrease of $H_{\mathrm{T}}$ from low to high latitudes. Therefore, 

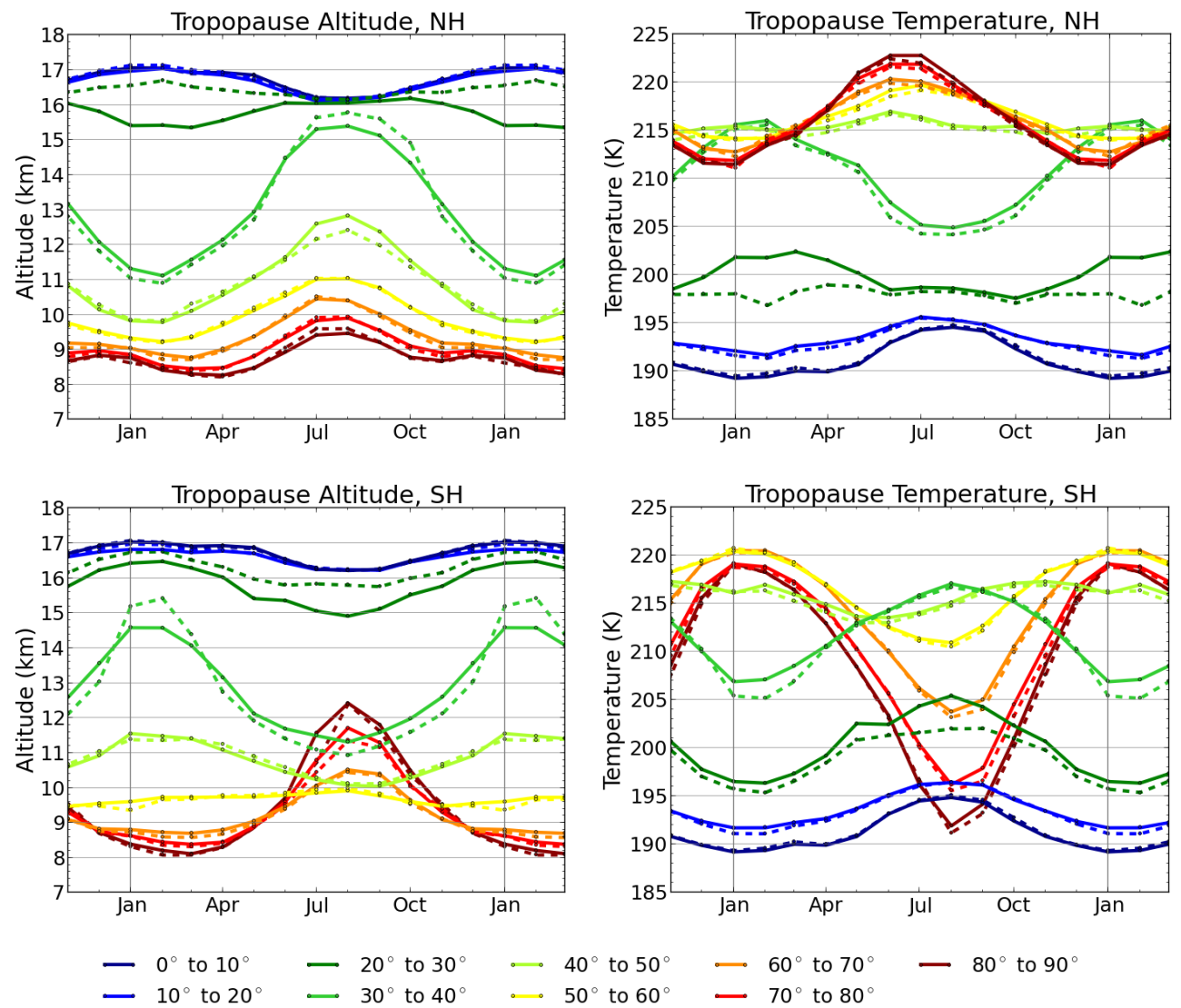

Figure 7. Annual cycle of mean (solid) and median (dashed) for tropopause altitude (left) and temperature (right) (top: NH; bottom: SH) using data from September 2001 to December 2013. Colors indicate different latitudinal bands. For clarity, two extra months are shown on either side of the full cycle.

the mean has a pronounced annual cycle, following that of mid latitudes. As a result, mean and median agree very well during summer in the $\mathrm{NH}$, but differences between mean and median increase in fall and maximize $(1 \mathrm{~km})$ in winter.

In the $\mathrm{SH}$, the situation is different, as the annual cycle of $H_{\mathrm{T}}$ has the same phase in the tropics and subtropics. The median is always higher than the mean, as more tropopauses show tropical characteristics. The resulting offset is $0.5 \mathrm{~km}$ in summer and $1 \mathrm{~km}$ in winter in the SH.

The shift from tropical to extra-tropical tropopause characteristics also causes minor differences between mean and median at latitudes from 30 to $50^{\circ} \mathrm{N} / \mathrm{S}$.

The mean annual cycle of $T_{\mathrm{T}}$ is shown in Fig. 7 (right panel). Again, high $H_{\mathrm{T}}$ corresponds to low $T_{\mathrm{T}}$, and vice versa. A weak annual cycle is found in the tropics with amplitudes of less than $3 \mathrm{~K}$. It increases towards mid latitudes to about $5 \mathrm{~K}$.

In the $\mathrm{NH}$, there is hardly any annual cycle for the 40 to $50^{\circ}$ latitudinal band, and a shift in phase towards high latitudes. Similar to Zängl and Hoinka (2001), we also find a single wave pattern of $T_{\mathrm{T}}$ with maximum temperatures in polar $\mathrm{NH}$ summer and minimum temperatures in winter in the
$\mathrm{NH}$, rather than a mixed wave pattern as found for $H_{\mathrm{T}}$. The amplitude of this $T_{\mathrm{T}}$ annual cycle ranges from 2.5 to $5 \mathrm{~K}$, increasing towards higher latitudes.

In the $\mathrm{SH}$, the annual cycle of $T_{\mathrm{T}}$ inversely follows that of $H_{\mathrm{T}}$ for all latitudes, including the 6-month shift of its phase from approximately $50^{\circ} \mathrm{S}$ polewards. In this region, the amplitude strongly increases with latitude to more than $12 \mathrm{~K}$ at polar latitudes. $T_{\mathrm{T}}$ is much lower in austral winter than in boreal winter. This difference is caused by the extremely cold polar vortex in the $\mathrm{SH}$, on the one hand, and the more frequent occurrence of sudden stratospheric warming (SSW) events in the NH on the other hand. During SSW events, stratospheric temperatures can increase by up to $50 \mathrm{~K}$ within a couple of days, which affects $T_{\mathrm{T}}$.

Differences in the mean and median of $T_{\mathrm{T}}$ correspond to differences in the mean and median of $H_{\mathrm{T}}$.

\section{Inter-annual variability}

As the tropopause is influenced by both tropospheric and stratospheric conditions, inter-annual anomalies in tropopause properties can be caused by events in the tropo- 

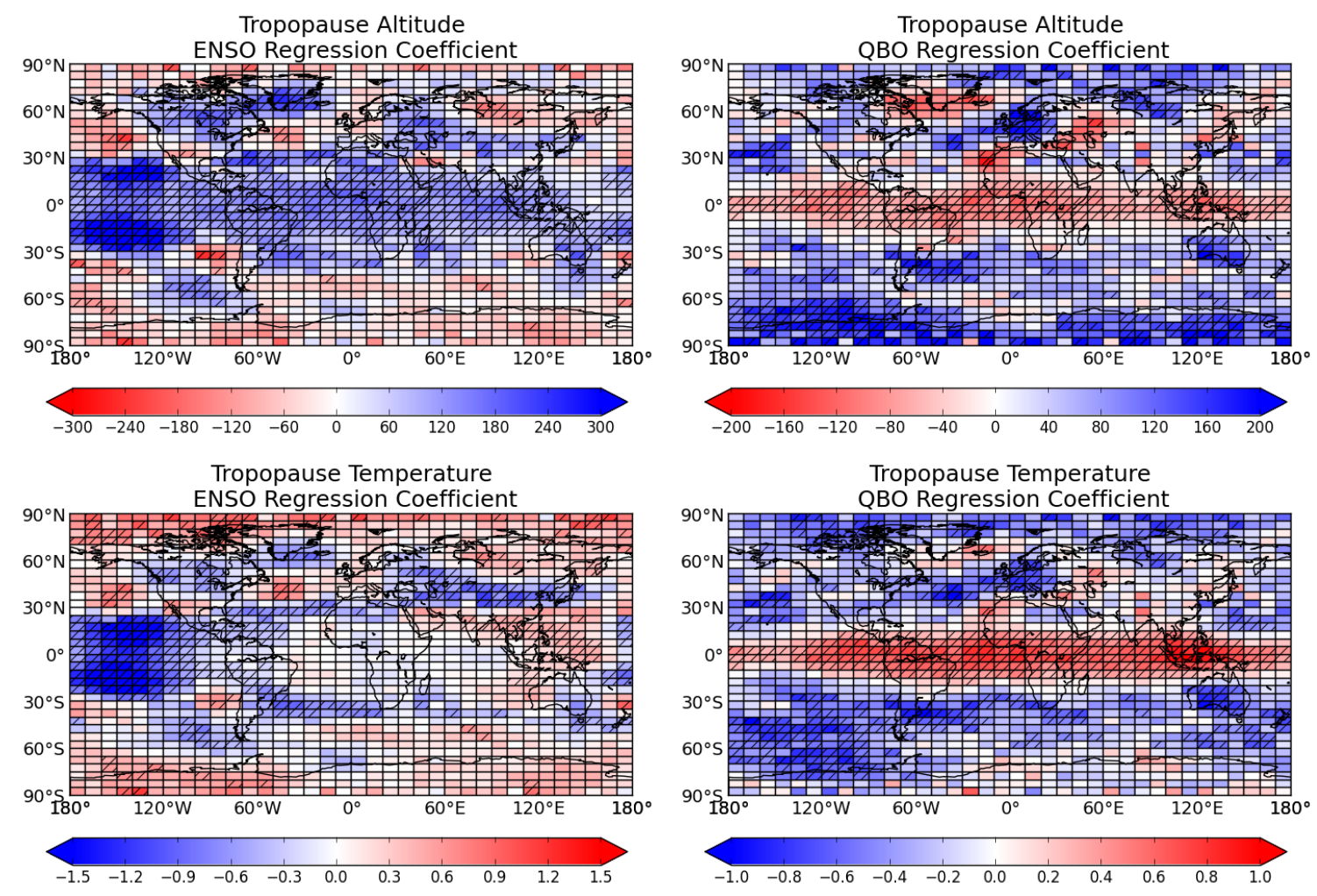

Figure 8. ENSO (left) and QBO (right) regression coefficients for the regression of tropopause altitude (top) and temperature (bottom). Units are meters $\left(H_{\mathrm{T}}\right.$ change) per kelvin or kelvin $\left(T_{\mathrm{T}}\right.$ change) per kelvin for ENSO regression coefficients and meters $\left(H_{\mathrm{T}}\right.$ change) per $10\left(\mathrm{~m} \mathrm{~s}^{-1}\right)$ or kelvin $\left(T_{\mathrm{T}}\right.$ change) per $10\left(\mathrm{~m} \mathrm{~s}^{-1}\right)$ for QBO regression coefficients. Hatched areas denote areas statistically significant at a significance level $\geq 95 \%$. Color bars of the ENSO and QBO coefficients are reversed for the regression of tropopause altitude and temperature for easier comparison (higher tropopauses are generally colder).

sphere, such as ENSO cold and warm phases, or in the stratosphere, such as SSW events or QBO.

ENSO has an impact on weather and climate on a global scale (Free and Seidel, 2009). ENSO warm phases cause tropospheric warming and stratospheric cooling (Lau et al., 1998). For zonal mean temperatures at low and mid latitudes, the ENSO signal shows a transition from warming to cooling near the tropopause. However, the transition of the local temperature response occurs well below the tropopause (Scherllin-Pirscher et al., 2012), yielding strong longitudinal variations of tropopause characteristics (Gage and Reid, 1987).

There was strong ENSO activity during the time range from 2007 to 2013. Major warm phases occurred during $2006 / 2007$ and 2009/2010, and major cold phases during 2007/2008, 2008/2009, 2010/2011, and 2011/2012.

Figure 8 depicts ENSO and QBO regression coefficients for the regression of tropopause altitude and temperature. The strongest ENSO signal occurs above the tropical central Pacific $\left(120\right.$ to $\left.180^{\circ} \mathrm{W}\right)$, where $H_{\mathrm{T}}$ correlates positively with ENSO warm phases and $T_{\mathrm{T}}$ correlates inversely with ENSO warm phases (please note that the color bars of the ENSO and QBO coefficients are reversed for the regression of tropopause altitude and temperature for easier comparison). Another ENSO signal occurs for $T_{\mathrm{T}}$ above the Maritime Continent $\left(100\right.$ to $\left.160^{\circ} \mathrm{E}\right)$, where $T_{\mathrm{T}}$ correlates positively with ENSO warm phases. These results agree well with the findings of Randel et al. (2000). QBO generally influences tropopause characteristics on a smaller scale and shows the out-of-phase character of the tropics and mid to high latitudes (Angell and Korshover, 1964). $T_{\mathrm{T}}$ and QBO anomalies correlate positively between $20^{\circ} \mathrm{S}$ and $20^{\circ} \mathrm{N}$ and are statistically significant for most bins. There are also some statistically significant areas at southern hemispheric mid and high latitudes, which agree well with results of Roy and Haigh (2011).

Furthermore, we analyze the zonal mean response of tropopause parameters to inter-annual atmospheric variability. Anomalies of the $H_{\text {mean }}$ (red) and $T_{\text {mean }}$ (blue) for the different latitudinal bands are shown in Fig. $9(\mathrm{NH})$ and Fig. 10 (SH) for September 2001 to December 2013.

In the tropics, variations are generally small with altitude (temperature) anomalies being smaller than $750 \mathrm{~m}(3 \mathrm{~K})$ for the observed time range. These variations are caused by a combination of QBO and ENSO (see above). Anomalies at latitudes between 20 and $50^{\circ}$ show some variability, but 


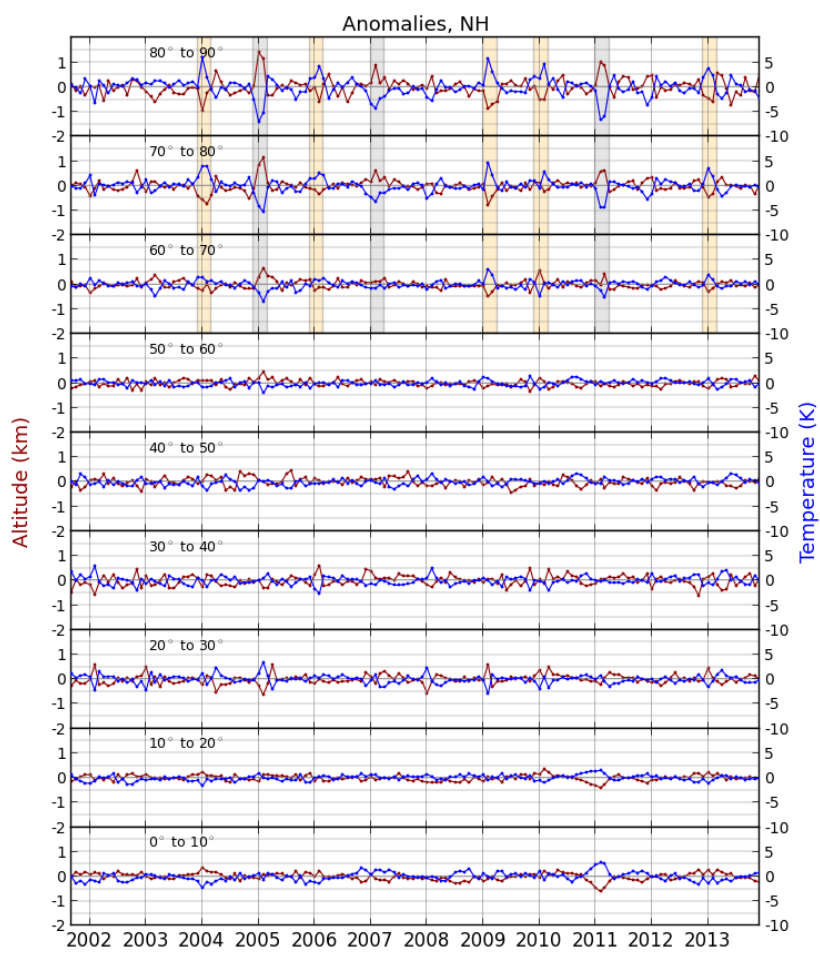

Figure 9. Anomalies of $H_{\mathrm{T}}$ (red) and $T_{\mathrm{T}}$ (blue) for $10^{\circ}$ latitudinal bands in the NH. Time range: September 2001 to December 2013. Months with strong sudden stratospheric warming (SSW) events are highlighted in orange; months with very weak or no events are highlighted in gray.

no distinct pattern. At high latitudes, however, stratospheric conditions have a strong impact on polar $H_{\mathrm{T}}$ and $T_{\mathrm{T}}$, especially in winter and spring.

SSW events have a relatively strong influence on tropopause characteristics. During SSW events, stratospheric temperatures can increase by up to $50 \mathrm{~K}$ within a couple of days (Kuttippurath and Nikulin, 2012) and cause low $H_{\mathrm{T}}$ and high $T_{\mathrm{T}}$.

In the $\mathrm{NH}$, relatively strong $\mathrm{SSW}$ events occurred in the winter of 2003/2004, 2005/2006, 2008/2009, 2009/2010, and 2012/2013 during the observed time range. Figure 9 shows lower $H_{\mathrm{T}}$ and higher $T_{\mathrm{T}}$ for these months. In January/February 2005, 2007, and 2011, when no or only a very weak SSW event occurred, tropopause anomalies were significantly higher and colder (up to $1.5 \mathrm{~km} / 7 \mathrm{~K}$ ) at high latitudes in the NH. Generally, the signal appears not only at polar latitudes, but between 60 and $90^{\circ} \mathrm{N}$.

During the observed time range, only one SSW event took place in the SH. In Fig. 10, $H_{\mathrm{T}}$ anomalies of $-2 \mathrm{~km}\left(T_{\mathrm{T}}\right.$ anomalies of $10 \mathrm{~K}$ ) can be seen late on in the year 2002 for the 80 to $90^{\circ} \mathrm{S}$ latitudinal band. This event was so strong that it even affected tropopause characteristics in the 50 to $60^{\circ} \mathrm{S}$ latitudinal band. Stratospheric conditions were also excep-

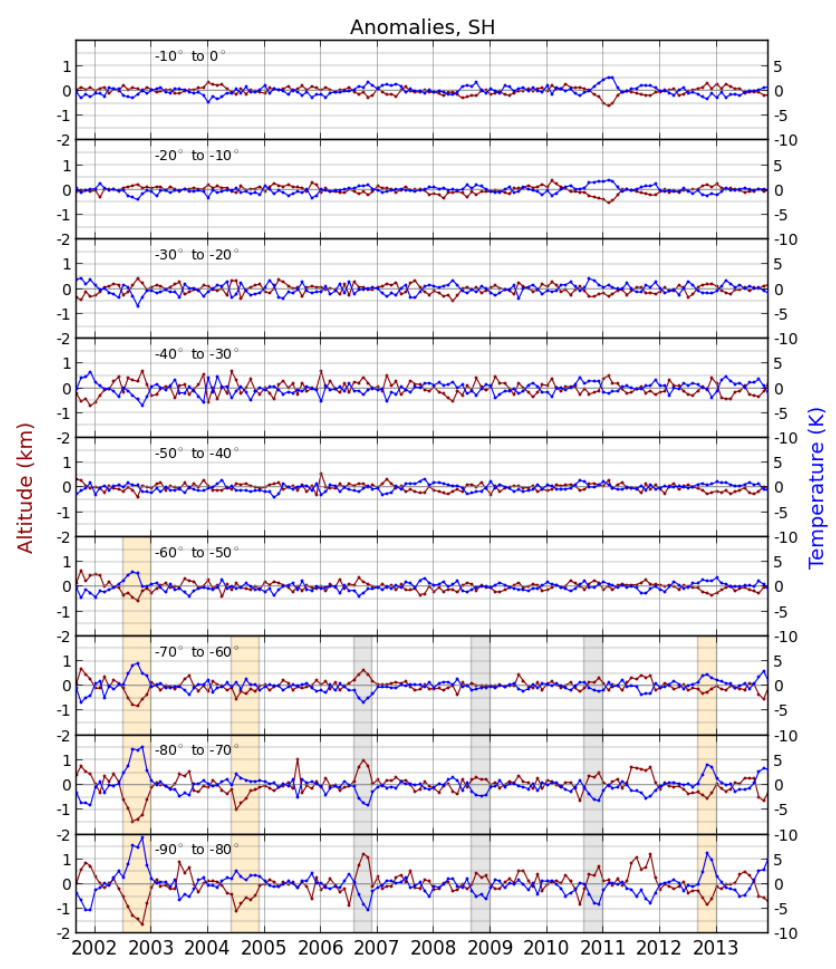

Figure 10. Anomalies of $H_{\mathrm{T}}$ (red) and $T_{\mathrm{T}}$ (blue) for $10^{\circ}$ latitudinal bands in the SH. Time range: September 2001 to December 2013. Months with exceptionally warm/cool stratospheric conditions are highlighted in orange and gray, respectively.

tionally warm for winter and spring $2004^{3}$ and spring $2012^{4}$ over the Antarctic region, yielding tropopause altitude and temperature anomalies of up to $-2 \mathrm{~km}$ and $7 \mathrm{~K}$. For the years 2006, 2008, 2010, and 2011, the polar vortex was very cold and stable, often until December ${ }^{3}$. This led to unusually cold stratospheric conditions and, as a consequence, to high $H_{\mathrm{T}}$ and low $T_{\mathrm{T}}$.

\section{Summary}

RO observations featuring high vertical resolution, global availability, and high accuracy, were used to investigate global characteristics of the lapse rate tropopause. Climatological tropopause characteristics for the RO record from 2001 to 2013 extend previous studies on the tropopause structure and its temporal variability. Latitudinal and longitudinal variations, as well as the annual cycle and inter-annual variability, were analyzed for tropopause altitude $\left(H_{\mathrm{T}}\right)$ and temperature $\left(T_{\mathrm{T}}\right)$.

Tropopause properties were analyzed using individual measurements, as well as averaged data. To obtain informa-

\footnotetext{
${ }^{3}$ http://www.cpc.ncep.noaa.gov/products/stratosphere/winter_ bulletins/

${ }^{4}$ http://www.theozonehole.com/2012ozonehole.htm
} 
tion about the latitudinal distribution of $H_{\mathrm{T}}$ and $T_{\mathrm{T}}$, the mean and its standard deviation, as well as median, quartiles, and extreme values (box-and-whisker plots) were shown for $5^{\circ}$ latitudinal bands for multi-year monthly averages.

$H_{\mathrm{T}}$ and $T_{\mathrm{T}}$ showed the well-known latitudinal structure with high and cold tropical tropopauses $(16$ to $17 \mathrm{~km} / 190$ to $195 \mathrm{~K}$ ) and lower and warmer extra-tropical tropopauses ( 8 to $12 \mathrm{~km} / \mathrm{up}$ to $230 \mathrm{~K}$ ). Double tropopauses were found at the Equator, close to the subtropical jets, and at winter hemispheric mid and high latitudes.

Variability in the subtropical tropopause break leads to a large spread in the $H_{\mathrm{T}}$ and $T_{\mathrm{T}}$ distribution in the 20 to $30^{\circ}$ latitudinal band during winter. Since the major part of tropopauses is located at high altitudes, but some tropopauses also show extra-tropical characteristics, the median $\left(H_{\text {med }}\right)$ is systematically higher than the mean $\left(H_{\text {mean }}\right)$. Differences exceed $1 \mathrm{~km}$ in both the $\mathrm{NH}$ and SH. Accordingly, $T_{\text {mean }}$ is up to $4 \mathrm{~K}$ higher than $T_{\text {med }}$.

For second tropopauses, the mean and median of $H_{\mathrm{T}}$ and $T_{\mathrm{T}}$ generally showed small differences. The distribution showed weak latitudinal variations, with most second tropopauses between 14 and $20 \mathrm{~km}$ in the extra-tropical winter hemisphere and between 18 and $20 \mathrm{~km}$ in the tropics.

Longitudinal variations of $H_{\mathrm{T}}$ and $T_{\mathrm{T}}$ occur due to land-sea coverage and orography. Zonal asymmetries at northern hemispheric mid latitudes $\left(40\right.$ to $\left.60^{\circ} \mathrm{N}\right)$ are caused by large-scale Rossby wave activity, most pronounced in boreal winter (Zängl and Hoinka, 2001). In boreal summer, strong convective activity in the Asian monsoon region leads to exceptionally high and cold tropopauses (Highwood and Hoskins, 1998).

The mean annual cycles of $H_{\mathrm{T}}$ and $T_{\mathrm{T}}$ vary strongly in amplitude with latitude. While smallest amplitudes were found in the tropics, amplitudes were largest at mid and southern hemispheric high latitudes. At northern hemispheric low latitudes, tropopause parameters follow the annual cycle of the BDC with maximum tropical upwelling in winter, leading to higher/colder tropopauses in winter than in summer. Therefore, the mean annual cycle is in phase within $20^{\circ} \mathrm{S}$ and $20^{\circ} \mathrm{N}$. A 6-month phase shift of the annual cycle was found over Antarctica. Due to the lack of incoming radiation in polar winter in the SH and the strong polar vortex, very low stratospheric temperatures lead to highest $H_{\mathrm{T}}$ (lowest $T_{\mathrm{T}}$ ) during that time of the year.

The mean annual cycle of $H_{\text {mean }}$ and $H_{\text {med }}$ ( $T_{\text {mean }}$ and $T_{\text {med }}$ ) agreed well for all latitudinal bands except 20 to $30^{\circ} \mathrm{N} / \mathrm{S}$. In this region, the mean was systematically lower than the median throughout the year. Furthermore, we showed that the 20 to $30^{\circ} \mathrm{N}$ median followed the tropical tropopause annual cycle as most tropopauses are located at high altitudes. The mean, however, is affected by some very low tropopauses that mainly occur during boreal winter and therefore followed the extra-tropical tropopause annual cycle.
Inter-annual variability of tropopause characteristics can be caused by both tropospheric and stratospheric events. An OLS regression analysis showed a strong ENSO signal above the tropical central Pacific and a QBO signal in the tropics, confirming previous studies on the influence of ENSO and QBO on tropopause altitude and temperature.

Furthermore, anomalies of averaged $H_{\mathrm{T}}$ and $T_{\mathrm{T}}$ showed signatures of both ENSO and QBO at low latitudes. At high latitudes, large anomalies could be attributed to strong variability of polar vortex strength, including SSW events.

The ability to detect reliable trends in the relatively short RO record is limited by the large atmospheric variability during the last couple of years (e.g., a strong El Niño event in 2009/2010 and two strong La Niña events in 2010/2011 and 2011/2012). Even for OLS regression analyses (including ENSO and QBO), tropopause trends were inconclusive for different periods (2001 to 2010; 2001 to 2012). Therefore, we did not include a discussion of tropopause parameter trends in this paper.

Acknowledgements. We thank two anonymous reviewers for their constructive comments and suggestions, which helped to improve the manuscript significantly. We would like to acknowledge UCAR/CDAAC for the provision of level 1 RO data and WEGC for the provision of level 2 RO data. Special thanks to M. Schwärz and J. Fritzer for the contributions in OPS system development and operations. This study was funded by the Austrian Science Fund (FWF) under research grants no. P22293-N21 (BENCHCLIM) and T620-N29 (DYNOCC).

Edited by: R. Anthes

\section{References}

Angell, J. K. and Korshover, J.: Quasi-Biennial Variations in Temperature, Total Ozone, and Tropopause Height, J. Atmos. Sci., 21, 479-492, doi:10.1175/15200469(1964)021<0479:QBVITT>2.0.CO;2, 1964.

Anthes, R. A.: Exploring Earth's atmosphere with radio occultation: contributions to weather, climate and space weather, Atmos. Meas. Tech., 4, 1077-1103, doi:10.5194/amt-4-1077-2011, 2011.

Baldwin, M. P., Gray, L. J., Dunkerton, T. J., Hamilton, K., Haynes, P. H., Randel, W. J., Holton, J. R., Alexander, M. J., Hirota, I., Horinouchi, T., Jones, D. B. A., Kinnersley, J. S., Marquardt, C., Sato, K., and Takahashi, M.: The Quasi-Biennial Oscillation, Rev. Geophys., 39, 179-229, 2001.

Birner, T.: Fine-scale structure of the extratropical tropopause region, J. Geophys. Res., 111, D04104, doi:10.1029/2005JD006301, 2006.

Birner, T.: Residual Circulation and Tropopause Structure, J. Atmos. Sci., 67, 2582-2600, doi:10.1175/2010JAS3287.1, 2010a.

Birner, T.: Recent widening of the tropical belt from global tropopause statistics: Sensitivities, J. Geophys. Res., 115, D23109, doi:10.1029/2010JD014664, 2010b. 
Borsche, M., Kirchengast, G., and Foelsche, U.: Tropical tropopause climatology as observed with radio occultation measurements from CHAMP compared to ECMWF and NCEP analyses, Geophys. Res. Lett., 34, L03702, doi:10.1029/2006GL027918, 2007.

Danzer, J., Foelsche, U., Scherllin-Pirscher, B., and Schwärz, M.: Influence of changes in humidity on dry temperature in GPS RO climatologies, Atmos. Meas. Tech., 7, 2883-2896, doi:10.5194/amt-7-2883-2014, 2014.

Foelsche, U., Borsche, M., Steiner, A. K., Gobiet, A., Pirscher, B., Kirchengast, G., Wickert, J., and Schmidt, T.: Observing upper troposphere-lower stratosphere climate with radio occultation data from the CHAMP satellite, Clim. Dynam., 31, 49-65, doi:10.1007/s00382-007-0337-7, 2008.

Foelsche, U., Pirscher, B., Borsche, M., Kirchengast, G., and Wickert, J.: Assessing the climate monitoring utility of radio occultation data: From CHAMP to FORMOSAT3/COSMIC, Terr. Atmos. Ocean. Sci., 20, 155-170, doi:10.3319/TAO.2008.01.14.01(F3C), 2009.

Free, M. and Seidel, D. J.: Observed El Niño-Southern Oscillation temperature signal in the stratosphere, J. Geophys. Res., 114, D23108, doi:10.1029/2009JD012420, 2009.

Fueglistaler, S., Dessler, A. E., Dunkerton, T. J., Folkins, I., Fu, Q., and Mote, P. W.: Tropical tropopause layer, Rev. Geophys., 47, RG1004, doi:10.1029/2008RG000267, 2009.

Gage, K. S. and Reid, G. C.: Longitudinal variations in tropical tropopause properties in relation to tropical convection and ENSO events, J. Geophys. Res., 92, 14197-14203, 1987.

Gettelman, A., Hoor, P., Pan, L. L., Randel, W. J., Hegglin, M. I., and Birner, T.: The extratropical upper troposphere and lower stratosphere, Rev. Geophys., 49, RG3003, doi:10.1029/2011RG000355, 2011.

Hajj, G. A., Kursinski, E. R., Romans, L. J., Bertiger, W. I., and Leroy, S. S.: A technical description of atmospheric sounding by GPS occultation, J. Atmos. Sol.-Terr. Phy., 64, 451-469, doi:10.1016/S1364-6826(01)00114-6, 2002.

Healy, S. B. and Eyre, J. R.: Retrieving temperature, water vapour and surface pressure information from refractive-index profiles derived by radio occultation: A simulation study, Q. J. Roy. Meteor. Soc., 126, 1661-1683, doi:10.1002/qj.49712656606, 2000.

Held, I. M.: On the height of the tropopause and the static stability of the troposphere, J. Atmos. Sci., 39, 412-417, 1982.

Highwood, E. J. and Hoskins, B. J.: The tropical tropopause, Q. J. Roy. Meteor. Soc., 124, 1579-1604, doi:10.1002/qj.49712454911, 1998.

Hoinka, K. P.: Statistics of the Global Tropopause Pressure, B. Am. Meteorol. Soc., 126, 3303-3325, doi:10.1175/15200493(1998)126<3303:SOTGTP>2.0.CO;2, 1998.

Holton, J. R., Haynes, P. H., McIntyre, M. E., Douglass, A. R., Rood, R. B., and Pfister, L.: Stratosphere-troposphere exchange, Rev. Geophys., 33, 403-439, doi:10.1029/95RG02097, 1995.

Homeyer, C. R., Bowman, K. P., and Pan, L. L.: Extratropical tropopause transition layer characteristics from highresolution sounding data, J. Geophys. Res., 115, D13108, doi:10.1029/2009JD013664, 2010.

Kishore, P., Namboothiri, S. P., Igarashi, K., Jiang, J. H., Ao, C. O., and Romans, L. J.: Climatological characteristics of the tropopause parameters derived from GPS/CHAMP and
GPS/SAC-C measurements, J. Geophys. Res., 111, D20110, doi:10.1029/2005JD006827, 2006.

Kuo, Y.-H., Wee, T.-K., Sokolovskiy, S., Rocken, C., Schreiner, W., Hunt, D., and Anthes, R. A.: Inversion and error estimation of GPS radio occultation data, J. Meteorol. Soc. Jpn., 82, 507-531, 2004.

Kursinski, E. R., Hajj, G. A., Schofield, J. T., Linfield, R. P., and Hardy, K. R.: Observing Earth's atmosphere with radio occultation measurements using the Global Positioning System, J. Geophys. Res., 102, 23429-23465, doi:10.1029/97JD01569, 1997.

Kuttippurath, J. and Nikulin, G.: A comparative study of the major sudden stratospheric warmings in the Arctic winters 2003/2004-2009/2010, Atmos. Chem. Phys., 12, 8115-8129, doi:10.5194/acp-12-8115-2012, 2012.

Lau, K.-M., Ho, C.-H., and Kang, I.-S.: Anomalous atmospheric hydrologic processes associated with ENSO: Mechanisms of Hydrologic Cycle-Radiation Interaction, J. Climate, 11, 800-815, doi:10.1175/1520-0442(1998)011<0800:AAHPAW>2.0.CO;2, 1998.

Leroy, S. S., Dykema, J. A., and Anderson, J. G.: Climate benchmarking using GNSS occultation, in: Atmosphere and Climate: Studies by Occultation Methods, edited by: Foelsche, U., Kirchengast, G., and Steiner, A. K., 287-302, Springer, Berlin, Heidelberg, 2006.

Lewis, H. W.: A robust method for tropopause altitude identification using GPS radio occultation data, Geophys. Res. Lett., 36, L12808, doi:10.1029/2009GL039231, 2009.

Melbourne, W. G., Davis, E. S., Duncan, C. B., Hajj, G. A., Hardy, K. R., Kursinski, E. R., Meehan, T. K., Young, L. E., and Yunck, T. P.: The application of spaceborne GPS to atmospheric limb sounding and global change monitoring, JPL Publication, 94-18, 147, 1994.

Nishida, M., Shimizu, A., and Tsuda, T.: Seasonal and Longitudinal Variations in the Tropical Tropopause Observed with the GPS Occultation Technique (GPS/MET), J. Meteorol. Soc. Jpn., 78, 691-700, 2000.

Randel, W. J., Wu, F., and Gaffen, D. J.: Interannual variability of the tropical tropopause derived from radiosonde data and NCEP reanalyses, J. Geophys. Res., 105, 15509-15523, doi:10.1029/2000JD900155, 2000.

Randel, W. J., Wu, F., and Ríos, W. R.: Thermal variability of the tropical tropopause region derived from GPS/MET observations, J. Geophys. Res., 108, 4024, doi:10.1029/2002JD002595, 2003.

Randel, W. J., Seidel, D. J., and Pan, L. L.: Observational characteristics of double tropopauses, J. Geophys. Res., 112, D07309, doi:10.1029/2006JD007904, 2007.

Reichler, T., Dameris, M., and Sausen, R.: Determining the tropopause height from gridded data, Geophys. Res. Lett., 30, 2042, doi:10.1029/2003GL018240, 2003.

Rieckh, T.: Tropopause Characteristics from GPS Radio Occultation Data, Wegener Center Verlag, Graz, Sci. Rep., 55-2013, 2013.

Roy, I. and Haigh, J. D.: The influence of solar variability and the quasi-biennial oscillation on lower atmospheric temperatures and sea level pressure, Atmos. Chem. Phys., 11, 11679-11687, doi:10.5194/acp-11-11679-2011, 2011.

Santer, B. D., Sausen, R., Wigley, T. M. L., Boyle, J. S., AchutaRao, K., Doutriaux, C., Hansen, J. E., Meehl, G. A., Roeckner, E., Ruedy, R., Schmidt, G., and Taylor, K. E.: Behavior of 
tropopause height and atmospheric temperature in models, reanalyses, and observations: Decadal changes, J. Geophys. Res., 108, D14002, doi:10.1029/2002JD002258, 2003.

Santer, B. D., Wigley, T. M. L., Simmons, A. J., Kallberg, P. W., Kelly, G. A., Uppala, S. M., Ammann, C., Boyle, J. S., Brüggemann, W., Doutriaux, C., Fiorino, M., Mears, C. A., Meehl, G. A., Sausen, R., Taylor, K. E., Washington, W. M., Wehner, M. F., and Wentz, F. J.: Identification of anthropogenic climate change using a second-generation reanalysis, J. Geophys. Res., 109, D21104, doi:10.1029/2004JD005075, 2004.

Sausen, R. and Santer, B. D.: Use of changes in tropopause height to detect human influences on climate, Meteorol. Z., 12, 131-136, doi:10.1127/0941-2948/2003/0012-0131, 2003.

Scherllin-Pirscher, B., Kirchengast, G., Steiner, A. K., Kuo, Y.H., and Foelsche, U.: Quantifying uncertainty in climatological fields from GPS radio occultation: an empirical-analytical error model, Atmos. Meas. Tech., 4, 2019-2034, doi:10.5194/amt-42019-2011, 2011.

Scherllin-Pirscher, B., Deser, C., Ho, S.-P., Chou, C., Randel, W., and Kuo, Y.-H.: The vertical and spatial structure of ENSO in the upper troposphere and lower stratosphere from GPS radio occultation measurements, Geophys. Res. Lett., 39, L20801, doi:10.1029/2012GL053071, 2012.

Schmidt, T., Wickert, J., Beyerle, G., and Reigber, C.: Tropical tropopause parameters derived from GPS radio occultation measurements with CHAMP, J. Geophys. Res., 109, D13105, doi:10.1029/2004JD004566, 2004.

Schmidt, T., Wickert, J., Beyerle, G., and Heise, S.: Global tropopause height trends estimated from GPS radio occultation data, Geophys. Res. Lett., 35, L11806, doi:10.1029/2008GL034012, 2008.

Schmidt, T., Wickert, J., and Haser, A.: Variability of the upper troposphere and lower stratosphere observed with GPS radio occultation bending angles and temperatures, Adv. Space Res., 46, 150-161, doi:10.1016/j.asr.2010.01.021, 2010.

Schwärz, M., Scherllin-Pirscher, B., Kirchengast, G., Schwarz, J., Ladstädter, F., Fritzer, J., and Ramsauer, J.: Multi-Mission Validation by Satellite Radio Occultation, Final report for ESA/ESRIN No. 01/2013, WEGC, 2013.

Seidel, D. J. and Randel, W. J.: Variability and trends in the global tropopause estimated from radiosonde data, J. Geophys. Res., 111, D21101, doi:10.1029/2006JD007363, 2006.
Seidel, D. J. and Randel, W. J.: Recent widening of the tropical belt: Evidence from tropopause observations, J. Geophys. Res., 112, D20113, doi:10.1029/2007JD008861, 2007.

Seidel, D. J., Ross, R. J., Angell, J. K., and Reid, G. C.: Climatological characteristics of the tropical tropopause as revealed by radiosondes, J. Geophys. Res., 106, 7857-7878, doi:10.1029/2000JD900837, 2001.

Smith, E. and Weintraub, S.: The constants in the equation for atmospheric refractive index at radio frequencies, Proc. IRE, 41, 1035-1037, 1953.

Son, S.-W., Lee, S., and Feldstein, S. B.: Intraseasonal variability of the zonal-mean extratropical tropopause height, J. Atmos. Sci., 64, 608-620, doi:10.1175/JAS3855.1, 2007.

Son, S.-W., Tandon, N. F., and Polvani, L. M.: The fine-scale structure of the global tropopause derived from COSMIC GPS radio occultation measurements, J. Geophys. Res., 116, D20113, doi:10.1029/2011JD016030, 2011.

Steiner, A. K., Lackner, B. C., Ladstädter, F., Scherllin-Pirscher, B., Foelsche, U., and Kirchengast, G.: GPS radio occultation for climate monitoring and change detection, Radio Sci., 46, RSOD24, doi:10.1029/2010RS004614, 2011.

Steiner, A. K., Scherllin-Pirscher, B., Brunner, L., Schwärz, M., and Kirchengast, G.: Temperature Trends in the Upper Troposphere to Lower Stratosphere from the Radio Occultation Climate Record 2002 to 2012, Poster presentation, AGU Fall Meeting, San Francisco, 9-13 December, 2013.

Thuburn, J. and Craig, G. C.: GCM tests of theories for the height of the tropopause, J. Atmos. Sci., 54, 869-882, doi:10.1175/15200469(1997)054<0869:GTOTFT>2.0.CO;2, 1997.

World Meteorological Organization (WMO), Meteorology - A three-dimensional science: Second session of the Commission for Aerology, WMO Bulletin, vol. IV(no. 4), 134-138, 1957.

Yulaeva, E., Holton, J. R., and Wallace, J. M.: On the cause of the annual cycle in tropical lower-stratospheric temperatures, J. Atmos. Sci., 51, 169-174, doi:10.1175/15200469(1994)051<0169:OTCOTA>2.0.CO;2, 1994.

Zängl, G. and Hoinka, K. P.: The tropopause in the polar regions, J. Climate, 14, 3117-3139, doi:10.1175/15200442(2001)014<3117:TTITPR>2.0.CO;2, 2001. 